\title{
OS CAMINHOS DA INSTITUCIONALIZAÇÃO DO ENSINO SUPERIOR DE HISTÓRIA
}

\section{THE PROCESS OF INSTITUTIONALIZATION OF THE TEACHING OF HISTORY AT GRADUATE LEVEL}

\author{
Norma Lucia da Silva ${ }^{1}$ \\ Marieta de Moraes Ferreira ${ }^{2}$
}

\begin{abstract}
RESUMO: Este artigo busca apresentar a trajetória de institucionalização dos cursos superiores de História no Brasil criados e/ou mantidos por instituições públicas. O objetivo principal é caracterizar um retrato dos cursos de História no país, desde o curso da Faculdade de Filosofia e Ciências Humanas da Universidade de São Paulo (USP), o primeiro a entrar em funcionamento, em 1934, até os últimos cursos, criados em 2010. A pesquisa foi realizada no banco de dados do Instituto Nacional de Pesquisas Educacionais Anísio Teixeira (INEP).
\end{abstract}

Palavras-chave: Cursos de História. Ensino Superior. Universidades.

\begin{abstract}
This article is aimed to present the process of institutionalization of graduate-level courses in History in Brazil created and/or maintained by public institutions. The main objective is to characterize a portrait of the courses in History in the country, starting with the course of the Faculdade de Filosofia e Ciências Humanas (School of Philosophy and Human Sciences) of the University of São Paulo (USP), which was the first established in Brazil, in 1934, and including the latest courses, in 2010. The research was carried out using data from the database of the Instituto Nacional de Pesquisas Educacionais Anísio Teixeira - INEP (National Institute for Research in Education Anísio Teixeira).
\end{abstract}

Keywords: History Course. Higher Education. Universities.

1 Universidade Federal do Tocantins.

2 Universidade Federal do Rio de Janeiro. 


\section{Introdução}

A institucionalização da História como disciplina universitária ocorreu, na maioria dos países da Europa e nos Estados Unidos, na segunda metade do século XIX e no início do século XX, quando, segundo Noiriel (NOIRIEL, 1990), o ensino superior torna-se um elemento central para a promoção social dos indivíduos, para a afirmação nacional, para a formação das elites e para o progresso científico e econômico. Essa institucionalização faz parte de um longo processo de transformação ocorrido nas instituições de ensino superior, permitindo a abertura e a consolidação de diversas áreas do conhecimento.

No Brasil, os primeiros cursos superiores foram criados pelas ordens religiosas $^{3}$, principalmente pelos jesuítas, que já no século XVI ofereciam cursos de Artes e Teologia. O curso de Artes, também chamado de Ciências Naturais ou Filosofia, tinha duração de três anos e abrangia o ensino de Lógica, Física, Matemática, Gramática e Retórica, conferindo os títulos de Bacharel e Licenciado aos concluintes. Já o curso de Teologia tinha duração de quatro anos, era dividido em Teologia Moral e Teologia Especulativa e conferia o título de doutor aos seus concluintes. Com a vinda da família real para o Brasil em 1808, houve uma reestruturação do ensino superior, tendo sido criados cursos e academias seculares com o objetivo principal de formar burocratas para o aparelho estatal, especialmente cursos de Medicina e Cirurgia e Matemática, em instituições militares, como a Academia Militar e a Academia da Marinha. Naquele período, os estudos de Matemática, Física, Química, Biologia e Mineralogia, que antes faziam parte dos cursos de Filosofia e eram controlados por religiosos, passaram a ser oferecidos pelos cursos médicos e pela Academia Militar. Os estudos de Filosofia, por sua vez, deslocaram-se para as faculdades de Direito. Data daquele período a criação dos cursos superiores, que por muito tempo seriam os únicos cursos a serem oferecidos no país: Medicina, em 1808, no

3 De acordo com Cunha (2007), as ordens franciscana, beneditina e carmelita também ofereciam ensino superior de Arte e Teologia, mas esses cursos eram voltados mais para a formação interna dos seus membros. 
Rio de Janeiro e na Bahia; Engenharia, em 1810, no Rio de Janeiro; e Ciências Jurídicas, em 1827, em São Paulo e em Olinda. Até a proclamação da República, em 1889, não ocorreram mudanças muito significativas no ensino superior, que se manteve, durante todo o Império, por iniciativa e manutenção estatal. Esses cursos e academias, no entanto, continuavam a funcionar em estabelecimentos isolados, não constituindo, ainda, universidades (CUNHA, 2007).

Luiz Antônio Cunha (2007) estaca que a primeira universidade propriamente dita foi a Universidade de Manaus, criada em 1909 por grupos privados ligados à exploração da borracha. Essa universidade reunia os cursos de Engenharia, Direito, Medicina, Farmácia, Odontologia e o Curso de Formação de Oficiais da Guarda Nacional. Com o declínio da borracha, ela foi fechada em 1926, só permanecendo em funcionamento o curso de Direito, que mais tarde seria incorporado à Universidade Federal do Amazonas, criada em 1962. Em 1911, em São Paulo, houve uma segunda tentativa de criação de uma universidade pela iniciativa privada: a Universidade de São Paulo, que oferecia os cursos de Medicina, Odontologia, Farmácia, Comércio, Direito e Belas Artes. Essa universidade foi extinta em 1917 devido à criação da Faculdade de Medicina pelo governo do estado, que atraiu os estudantes, inviabilizando a instituição em termos financeiros. Uma terceira universidade foi criada em Curitiba, em 1912, por profissionais locais incentivados pelo governo estadual. A instituição oferecia os cursos de Direito, Engenharia, Medicina, Farmácia, Odontologia e Comércio. Em 1917, no entanto, ela teve de ser extinta por força do Decreto Federal de $1915^{4}$, que não permitia mais que instituições de ensino superior instaladas em cidades com menos de 100 mil habitantes fossem equiparadas às instituições federais. Em 1920, no Rio de Janeiro, foi criada a primeira universidade duradoura do país: a Universidade do Rio de Janeiro - que, a partir de 1937, passaria a se chamar Universidade do Brasil. Essa instituição foi constituída pela junção das faculdades de Medicina,

4 Segundo Cunha, desde as reformas educacionais de 1891, as instituições superiores (estaduais ou privadas) que tivessem o mesmo currículo das instituições federais e se submetessem à fiscalização do governo federal tinham seus cursos e diplomas equiparados aos das instituições oficiais. 
Engenharia, Direito e de duas instituições privadas que foram federalizadas. Ela serviria de modelo para as demais universidades criadas no país a partir daquele momento, através da junção de faculdades e cursos pré-existentes, como a Universidade de Minas Gerais, criada em 1927 pela aglutinação das faculdades de Engenharia, Direito, Medicina, Odontologia e Farmácia, já existentes em Belo Horizonte. Uma exceção a esse modelo naquele período foi a Universidade do Rio Grande do Sul, criada em 1934 pela diferenciação de uma única faculdade, a Escola de Engenharia de Porto Alegre, que oferecia, além de cursos ligados à Engenharia, os cursos de Agronomia, Veterinária, Química e de formação de operários industriais e agrícolas.

\section{A Institucionalização do Ensino Superior de História}

Os primeiros cursos superiores de História no Brasil foram institucionalizados pela Faculdade de Filosofia, Ciências e Letras da Universidade de São Paulo, em 1934, e pela Universidade do Distrito Federal (UDF), em 1935, que mais tarde (1939) seria reestruturado na Faculdade Nacional de Filosofia (FNFi) da Universidade do Brasil, atual Universidade Federal do Rio de Janeiro. Cada curso foi fundado por razões locais específicas, mas geralmente estava associado a um projeto político mais amplo. Com exceção do curso da UDF, os demais cursos eram oferecidos de forma integrada à Geografia. Somente a partir de 1955, com a Lei $2.594^{5}$, esses cursos se tornaram independentes.

A década de 1930, quando foram criados os primeiros cursos de história, foi marcada pelo surgimento de um novo Estado, distanciado daquelas características oligárquicas do período anterior.

O novo governo preocupou-se com a formação de uma elite mais ampla e intelectualmente mais preparada. Assim, formatou um modelo de

\footnotetext{
${ }^{5}$ A lei no 2.594, de 08 de setembro de 1955, dispõe sobre o desdobramento dos cursos de Geografia e História nas faculdades de Filosofia. Disponível em : <www2.camara.gov.br/legin/fed/lei/1950-1959/lei-2594-8-setembro-1955-361157publicacao-1-pl.html>. Acesso em: 03 jul. 2010.
} 
sistema educativo laico, partindo do centro para a periferia, ou seja, da capital do país para o interior. Ocupou-se de reformas educacionais, iniciadas com a criação do Ministério da Educação e Saúde Pública, entregue inicialmente a Francisco Campos, jurista mineiro, que acabou por implementar um modelo educativo ligado aos ideais escolanovistas. Daí o fato de esse modelo ter provocado uma forte reação dos setores católicos, que ainda exerciam uma influência relevante no campo educacional brasileiro (GHIRALDELLI JR., 2008) ${ }^{6}$.

Francisco Campos (1891-1968) preocupou-se principalmente com os ensinos superior e secundário, preconizando que este último deveria ser implantado em outras bases, deixando de ser um mero curso preparatório para o ingresso no ensino superior. Os decretos 19.890, de 18/04/1931, e 21.241, de 04/04/1932, estabeleciam para esse nível de ensino um currículo seriado, com frequência obrigatória, em dois ciclos: um fundamental de cinco anos e outro complementar de dois anos (Idem).

A Reforma Francisco Campos, como ficou conhecida, criou, ainda, o Conselho Nacional de Educação (Decreto 19.850, de 11/04/1931); a regulamentação do ensino superior (Decreto 19.851, de 11/04/1931); e a organização da Universidade do Rio de Janeiro (Decreto 19.852, de 11/04/1931). (ROMANELLI, 2009). Esta seria formada pela Escola de Minas, pelas Faculdades de Farmácia e Odontologia, pela Escola de Belas Artes, pelo Instituto Nacional de Música, além das faculdades já existentes desde 1920 (Faculdade de Direito, Faculdade de Medicina e Escola Politécnica). Buscava-se, com isso, estabelecer as bases do sistema universitário brasileiro. Embora o ministro Campos tenha desempenhado um importante papel no processo de reformas educacionais no país, as grandes transformações se dariam na gestão de outro ministro: Gustavo Capanema.

Capanema assumiu o Ministério da Educação e Saúde em 1934, nele permanecendo até 1945, com a queda de Getúlio Vargas e do Estado Novo. Em 1936, elaborou um inquérito sobre a educação nacional, com um

6 Para Ghiraldelli Jr. (2008), a Igreja Católica, especialmente nas figuras de Alceu Amoroso Lima, Leonardo Van Acker e Alexandre Correia, buscou, inicialmente, bloquear o movimento escolanovista, lançando duras críticas aos ideais libertários da pedagogia Deweyana. 
questionário de mais de 200 questões, que fundamentaria o Plano Nacional de Educação de 1937. O plano mantinha o formato estabelecido por Francisco Campos para o ensino secundário e determinava normas gerais para o funcionamento das instituições educativas (públicas e privadas) em todo o país, além de regulamentar a liberdade de cátedra, o ensino de Religião, de Educação Moral e Cívica e de Educação Física. Os cursos deveriam ser ministrados por professores catedráticos, escolhidos por concurso, com título obrigatório obtido pela Faculdade de Filosofia, Ciências e Letras, uma vez em funcionamento. O ensino superior teve maior destaque no plano, reservando ao Conselho Nacional de Educação o direito de autorizar e regular a criação de universidades, além de controlar a autonomia "administrativa, didática e disciplinar". O plano trazia, ainda, um detalhamento de como deveria ser a estrutura ideal, formada por departamentos, faculdades, institutos e órgãos associados. Os professores deveriam ser divididos em catedráticos, contratados, livres-docentes e auxiliares. Os cursos, por sua vez, tinham um conteúdo mínimo a ser ensinado, além da seriação e das opções que poderiam ser feitas pelos alunos (SCHWARTZMAN; BOMENY; COSTA, 2000).

Em 1937, foi criada a Universidade do Brasil (UB) pela Lei Federal no 452, de 5 de julho, que tratava da organização da UB. Seu artigo $1^{0}$ determinava o seguinte: "A Universidade do Brasil é uma comunidade de professores e alunos, consagrados ao estudo". O artigo 20 afirmava: "A Universidade do Brasil terá por finalidades essenciais: a) o desenvolvimento da cultura filosófica, científica, literária e artística; b) a formação de quadros donde se recrutem elementos destinados ao magistério bem como às altas funções da vida pública do país; c) o preparo de profissionais para o exercício de atividades que demandem estudos superiores" ${ }^{\prime 7}$.

Um dos objetivos da criação da UB era torná-la um modelo de ensino superior para todo o país e controlar a qualidade de ensino das demais instituições de nível superior, assim como o Colégio Pedro II fora para o ensino secundário. A principal mudança em relação à Reforma Francisco

Lei $\quad n^{\circ} \quad 452, \quad$ de $\quad 5$ de julho de $1937 . \quad$ Disponível em:
<www.lexml.gov.br/urn/urn:lex:br:federal:lei:1937-07-05;452>. Acesso em: 3 fev. 2010. 
Campos era a criação de um campus universitário, agrupando-se fisicamente os diversos institutos e faculdades e tendo-se a Faculdade de Filosofia, Ciências e Letras como núcleo de integração de todos eles (Lei n. 452).

Embora tivesse um projeto universitário ousado, Capanema, desde o início, manteve uma relação amistosa com os setores conservadores católicos, que se empenharam em solicitar ao ministro que excluísse dos quadros universitários os intelectuais liberais, que permitisse a criação e/ou manutenção de instituições superiores privadas $^{8}$ vinculadas à Igreja e a manutenção do ensino religioso na educação básica.

\section{O Curso de Geografia e História da USP (1934)}

A Universidade de São Paulo (USP) foi a primeira universidade organizada segundo as diretrizes da Reforma Capanema, viabilizada em grande medida pela ação do interventor estatal, Armando Salles de Oliveira, nomeado pelo governo Vargas, que, junto com Júlio de Mesquita Filho e Fernando Azevedo, protagonizou o processo de criação da USP. A universidade teria como objetivos principais, segundo seus fundadores, 0 desenvolvimento de uma elite intelectual para dirigir o país e a formação de professores para os ensinos secundário e superior, elementos que justificariam o empenho, desde o início, também para a criação da Faculdade de Filosofia, Ciências e Letras (ROIZ, 2004).

A Faculdade de Filosofia, Ciências e Letras foi criada pelo mesmo Decreto Estadual no 6.283, de 25 de janeiro de 1934, que instituía a Universidade de São Paulo e agregava os cursos de licenciatura em Filosofia, Ciências Matemáticas, Ciências Físicas, Ciências Sociais e Políticas,

8 De acordo com Schwatzman et al.(op. cit.), nesse período foram criadas várias universidades católicas, como PUC/RS (1940), PUC-Rio (1941), PUC-Campinas (1942), PUC-Minas (1943), Universidade Católica de Pernambuco (1943). 
Letras Clássicas e Português e Geografia e História ${ }^{9}$, organizados segundo as diretrizes nacionais.

O curso de Geografia e História teria a função, além de preparar professores para todos os níveis de ensino, de cuidar da história do país, da sua diversidade étnica e linguística, ainda pouco conhecidas. Ele foi estruturado no regime de cátedras, organizado em três anos com a seguinte estrutura curricular:

\begin{tabular}{|c|c|c|c|}
\hline Ano & Primeiro & Segundo & Terceiro \\
\hline Disciplinas & Geografia & Geografia & Geografia \\
\cline { 2 - 4 } & História da Civilização & História da Civilização & $\begin{array}{c}\text { História da } \\
\text { Civilização } \\
\text { Brasileira }\end{array}$ \\
\cline { 2 - 4 } & $\begin{array}{c}\text { Etnologia Brasileira e } \\
\text { Noç̃̃es de Tupi- } \\
\text { guarani. }\end{array}$ & Tupi-guarani & $\begin{array}{l}\text { História da } \\
\text { Civilização }\end{array}$ \\
\cline { 2 - 4 } & $\begin{array}{c}\text { História da Civilização } \\
\text { Americana (inclusive pré- } \\
\text { história). }\end{array}$ & Tupi-guarani \\
\hline
\end{tabular}

Fonte: Anuário da Faculdade de Filosofia, Ciências e Letras, 1934-1935, 1937. (ROIZ, 2004, p. 68).

Em 1939, a estrutura curricular do curso passou por sua primeira reestruturação, atendendo ao disposto no Decreto Federal no 1.190, de 04 de abril de 1939, que regulamentava a organização da Faculdade Nacional de Filosofia. Em seu artigo 14 tratava da organização do curso de Geografia e História, que deveria ser oferecido em três anos com a seguinte seriação de disciplinas: $1^{\text {a }}$ Série (Geografia Física, Geografia Humana, Antropologia e História da Antiguidade e da Idade Média); 2a série (Geografia Física, Geografia Humana, História Moderna, História do Brasil e Etnografia); e $3^{a}$ série (Geografia do Brasil, História Contemporânea, História do Brasil,

${ }^{9}$ Os cursos de Geografia e História da USP foram unificados até 1956, quando se tornaram cursos independentes, adequando-se ao Decreto Federal no 2.594, de 1955, que determinava a separação dos cursos (ROIZ, 2004). 
História da América e Etnografia do Brasil) ${ }^{10}$. Assim, o curso de História da USP transformou a cadeira de Geografia em duas novas cadeiras (Geografia Física e Geografia Humana) e a cadeira de História das Civilizações nas cadeiras de História da Civilização Antiga e Medieval e História da Civilização Moderna e Contemporânea. Em 1942, também para se adaptar às determinações do Decreto 1.190, foi incluído o Curso de Didática, no qual passariam a ser ministradas as disciplinas de formação pedagógica. A partir de então, a estrutura curricular passou a ser a seguinte:

\begin{tabular}{|c|c|c|c|c|}
\hline Ano & Primeiro & Segundo & Terceiro & Quarto \\
\hline \multirow{6}{*}{ Disciplinas } & Geografia Física & $\begin{array}{l}\text { Geografia } \\
\text { Física }\end{array}$ & Geografia do Brasil & Didática Geral \\
\hline & $\begin{array}{l}\text { Geografia } \\
\text { Humana }\end{array}$ & $\begin{array}{c}\text { Geografia } \\
\text { Humana }\end{array}$ & $\begin{array}{c}\text { História da } \\
\text { Civilização } \\
\text { Contemporânea }\end{array}$ & Didática Especial \\
\hline & Antropologia & $\begin{array}{l}\text { História da } \\
\text { Civilização } \\
\text { Moderna }\end{array}$ & $\begin{array}{c}\text { História da } \\
\text { Civilização } \\
\text { Brasileira }\end{array}$ & $\begin{array}{l}\text { Psicologia } \\
\text { Educacional }\end{array}$ \\
\hline & $\begin{array}{c}\text { História da } \\
\text { Civilização } \\
\text { Antiga e } \\
\text { Medieval } \\
\end{array}$ & $\begin{array}{l}\text { História da } \\
\text { Civilização } \\
\text { Brasileira }\end{array}$ & $\begin{array}{l}\text { História da } \\
\text { Civilização } \\
\text { Americana }\end{array}$ & $\begin{array}{c}\text { Administração } \\
\text { Escolar e } \\
\text { Educação } \\
\text { Comparada } \\
\end{array}$ \\
\hline & $\begin{array}{c}\text { Elementos de } \\
\text { Geologia }\end{array}$ & Etnografia & $\begin{array}{c}\text { Etnografia do } \\
\text { Brasil e Língua } \\
\text { Tupi-guarani }\end{array}$ & $\begin{array}{c}\text { Fundamentos } \\
\text { Biológicos da } \\
\text { Educação }\end{array}$ \\
\hline & & & & $\begin{array}{l}\text { Fundamentos } \\
\text { Sociológicos da } \\
\text { Educação }\end{array}$ \\
\hline
\end{tabular}

Fonte: Anuário da Faculdade de Filosofia, Ciências e Letras, 1939-1949, 1953. (ROIZ, 2004, p. 86).

Na nova estrutura, as disciplinas de formação pedagógica ficavam concentradas no quarto ano. Os alunos que concluíssem os três primeiros anos do curso obtinham o diploma de Bacharel, necessário para o ingresso no curso de Didática. Os concluintes do curso de Didática obtinham, ainda, o diploma de Licenciado. Nesse período, também foram reestruturadas as disciplinas de Geografia e História. A disciplina de História da Civilização Brasileira, antes ministrada no terceiro ano do curso, passou a ser lecionada

10 Decreto Federal no 1.190, de 04 de abril de 1939. Disponível em: <www2.camara.gov.br/legin/fed/declei/1930-1939/decreto-lei-1190-4-abril-1939-349241publicacao-1-pe.html>. Acesso em: 03 jul. 2010. 
também no segundo ano. A disciplina de História da Civilização Americana, ministrada no segundo ano, passou a ser ensinada no terceiro. Além das disciplinas de Geografia Física e Geografia Humana, foi incluída a de Geografia do Brasil. A disciplina de Etnologia Brasileira e Noções de Tupiguarani e a disciplina de Tupi-guarani foram reformuladas, passando a ser oferecidas as disciplinas de Antropologia no primeiro ano, de Etnografia no segundo e de Etnografia do Brasil e Língua Tupi-guarani no terceiro. Também foi incluída, no primeiro ano, a disciplina de Elementos da Geologia.

Uma nova reestruturação curricular foi implementada em 1946, quando no quarto ano os alunos poderiam escolher livremente duas ou três disciplinas oferecidas pelos cursos da Faculdade de Filosofia, obtendo o diploma de Bacharel após a sua conclusão. Para também obterem o diploma de Licenciado, eles deveriam cursar, além do curso de Didática, o curso de Psicologia ligada à educação.

Em 1956, o curso de Geografia e História foi dividido, tornado-se cursos independentes para atender à Lei Federal no 2.594, de 1955 ${ }^{11}$. A estrutura do curso de História, a partir daquele momento independente, manteve uma única disciplina de Geografia no primeiro ano, desmembrou a disciplina de História da Civilização Antiga e Medieval em duas (História da Civilização Antiga e História da Civilização Medieval) e incluiu a disciplina de Introdução aos Estudos Históricos no primeiro ano. No segundo ano, mantiveram-se as disciplinas de História da Civilização Moderna, História da Civilização Americana e História da Civilização Brasileira, acrescentando-se a disciplina de História da Civilização Ibérica e outra optativa. No terceiro ano, a única modificação foi a inclusão de uma disciplina optativa. As disciplinas optativas oferecidas no segundo e no terceiro ano pelo curso de História foram as seguintes: História das Ideias Políticas; História da Filosofia; História Econômica; História da Educação; História da Literatura (Inglesa ou Espanhola, Alemã, Francesa, Latina, Grega, Portuguesa e

${ }^{11}$ A Lei no 2.594, de 08 de setembro de 1955, dispõe sobre o desdobramento dos cursos de Geografia e História nas faculdades de Filosofia. Disponível em: <www2.camara.gov.br/legin/fed/lei/1950-1959/lei-2594-8-setembro-1955-361157publicacao-1-pl.html>. Acesso em: 03 jul. 2010. 
Brasileira); História da Arte; Numismática e Paleografia. Como na estrutura anterior, no quarto ano os alunos podiam optar livremente por duas ou três cadeiras dos cursos da Faculdade de Filosofia para obtenção do diploma de Bacharel. Para conseguirem o diploma de Licenciado, deveriam cursar, ainda, as disciplinas de Psicologia e de Didática (ROIZ, 2004).

\begin{tabular}{|c|c|c|c|c|}
\hline Ano & Primeiro & Segundo & Terceiro & Quarto \\
\hline \multirow{6}{*}{ Disciplinas } & $\begin{array}{c}\text { Introdução aos } \\
\text { Estudos } \\
\text { Históricos }\end{array}$ & $\begin{array}{l}\text { História da } \\
\text { Civilização } \\
\text { Moderna }\end{array}$ & $\begin{array}{c}\text { História da } \\
\text { Civilização } \\
\text { Contemporânea }\end{array}$ & \\
\hline & $\begin{array}{l}\text { História da } \\
\text { Civilização } \\
\text { Antiga }\end{array}$ & $\begin{array}{l}\text { História da } \\
\text { Civilização } \\
\text { Brasileira }\end{array}$ & $\begin{array}{c}\text { História da } \\
\text { Civilizaçãa } \\
\text { Brasileira } \\
\end{array}$ & \\
\hline & $\begin{array}{l}\text { História da } \\
\text { Civilização } \\
\text { Medieval }\end{array}$ & $\begin{array}{l}\text { História da } \\
\text { Civilização } \\
\text { Americana }\end{array}$ & $\begin{array}{l}\text { História da } \\
\text { Civilização } \\
\text { Americana }\end{array}$ & \\
\hline & Antropologia & Etnografia Geral & $\begin{array}{c}\text { Etnografia do Brasil } \\
\text { e Noções de Tupi- } \\
\text { guarani }\end{array}$ & \\
\hline & Geografia & $\begin{array}{c}\text { História da } \\
\text { Civilização Ibérica }\end{array}$ & Disciplina Optativa & \\
\hline & & $\begin{array}{l}\text { Disciplina } \\
\text { Optativa }\end{array}$ & & \\
\hline
\end{tabular}

Fonte: Revista de História. São Paulo/USP, 12 (25): 285-86, jan./mar. 1956. (ROIZ, 2004, p. 94).

\section{O Curso de História da UDF/FNFi $\left(1935^{12}\right)$}

Diferentemente do curso de História da Faculdade de Filosofia, Ciências e Letras da Universidade de São Paulo, o curso de História da Universidade do Distrito Federal (UDF) ${ }^{13}$ - criado pelo Decreto Municipal no 5.513, de 1935, assinado pelo prefeito Pedro Ernesto - foi instituído como independente do curso de Geografia. Ele fazia parte da Escola de Direito e Economia, que também integrava os cursos de Geografia, Ciências Sociais,

12 Nos registros do INEP a data de início do curso é 11/04/1931. Supomos que esta data se refira à autorização do curso pela Universidade do Rio de Janeiro, criada em 1920. Essa universidade foi transformada em Universidade do Brasil, em 1937, e em Universidade Federal do Rio de Janeiro, em 1965.

13 A UDF, criada pelo Decreto 5.513, de 1935, era formada, além da Faculdade de Direito e Economia, pelo Instituto de Educação, pela Escola de Ciências, pela Escola de Filosofia e Letras, pelo Instituto de Artes e pelo Instituto de Artes para Experimentação Pedagógica (FERREIRA, 2006, p. 142). 
Ciências Econômicas, Ciências Jurídicas e Ciências Políticas. O curso foi estruturado em três anos, divididos em três eixos: Cursos de Conteúdo, Cursos de Fundamento e Cursos de Integração Profissional, conforme quadro a seguir.

\begin{tabular}{|c|c|c|c|}
\hline & Primeiro Ano & Segundo Ano & Terceiro Ano \\
\hline \multirow[t]{4}{*}{$\begin{array}{l}\text { Cursos de } \\
\text { Conteúdo }\end{array}$} & $\begin{array}{l}\text { História da } \\
\text { Antiguidade }\end{array}$ & $\begin{array}{l}\text { História da Idade } \\
\text { Contemporânea }\end{array}$ & \\
\hline & $\begin{array}{l}\text { História da Idade } \\
\text { Média e dos } \\
\text { Tempos Modernos }\end{array}$ & $\begin{array}{c}\text { História da Civilização } \\
\text { na América }\end{array}$ & \\
\hline & & $\begin{array}{c}\text { História da Civilização } \\
\text { no Brasil }\end{array}$ & \\
\hline & & $\begin{array}{l}\text { Organização do } \\
\text { Programa e do } \\
\text { Material Didático de } \\
\text { Geografia e História }\end{array}$ & \\
\hline \multirow{4}{*}{$\begin{array}{l}\text { Cursos de } \\
\text { Fundamento }\end{array}$} & Antropologia & Biologia Educacional & \\
\hline & Desenho & Desenho & \\
\hline & Geografia Humana & $\begin{array}{c}\text { Inglês ou Alemão - } \\
\text { opcional }\end{array}$ & \\
\hline & $\begin{array}{l}\text { Inglês ou Alemão - } \\
\text { opcional }\end{array}$ & $\begin{array}{l}\text { Sociologia } \\
\text { Educacional }\end{array}$ & \\
\hline \multirow{6}{*}{$\begin{array}{l}\text { Cursos de } \\
\text { Integração } \\
\text { Profissional }\end{array}$} & & & Introdução ao Ensino \\
\hline & & & Filosofia da Educação \\
\hline & & & $\begin{array}{l}\text { Psicologia do } \\
\text { Adolescente }\end{array}$ \\
\hline & & & $\begin{array}{c}\text { Medidas } \\
\text { Educacionais, } \\
\text { Organização e } \\
\text { Programas do Ensino } \\
\text { Secundário }\end{array}$ \\
\hline & & & Filosofia das Ciências \\
\hline & & & Prática de Ensino \\
\hline
\end{tabular}

Fonte: Instruções no 3 da UDF, de 12 de junho de 1935, e Instruções $n^{\circ} 16$, de 25 de junho de 1937. Arquivo do Instituto de Educação. (FERREIRA, 2006, p. 144-145).

O curso de História da UDF tinha uma proposta bastante diferente da do curso da USP. Na verdade, este último seguia as determinações da Reforma de Francisco Campos, enquanto o curso da UDF "passava ao largo das orientações do Ministério da Educação". Primeiro por ter sido, desde a 
sua criação, um curso independente do de Geografia. Depois, por privilegiar conteúdos voltados para a formação de professores, com uma quantidade significativa de disciplinas de formação pedagógica: Introdução ao Ensino, Filosofia da Educação, Psicologia do Adolescente, Medidas Educacionais, Organização e Programas do Ensino Secundário, Filosofia das Ciências e Prática de Ensino, oferecidas no terceiro ano. As disciplinas dos Cursos de Fundamento tinham um caráter de formação mais geral, mas também continham disciplinas voltadas para a área pedagógica, como Biologia Educacional e Sociologia Educacional, no segundo ano, o que revela o peso bastante significativo dessas disciplinas no curso (FERREIRA, 2006).

Em 1937, a estrutura curricular do curso sofreu sua primeira modificação, seguindo várias orientações de professores franceses, especialmente as de Henri Hauser. A nova estrutura curricular passou a ser a seguinte:

\begin{tabular}{|c|c|c|c|}
\hline & Primeiro Ano & Segundo Ano & Terceiro Ano \\
\hline \multirow{5}{*}{$\begin{array}{l}\text { Cursos de } \\
\text { Conteúdo }\end{array}$} & $\begin{array}{l}\text { História da } \\
\text { Antiguidade }\end{array}$ & $\begin{array}{c}\text { História } \\
\text { Contemporânea }\end{array}$ & História Contemporânea \\
\hline & & História Moderna & $\begin{array}{c}\text { Pesquisas Históricas e } \\
\text { Bibliografia }\end{array}$ \\
\hline & História Medieval & $\begin{array}{l}\text { História da } \\
\text { Civilização na } \\
\text { América }\end{array}$ & \\
\hline & História Moderna & $\begin{array}{c}\text { História da } \\
\text { Civilização no } \\
\text { Brasil }\end{array}$ & \\
\hline & & História Antiga & \\
\hline \multirow[b]{2}{*}{$\begin{array}{l}\text { Cursos de } \\
\text { Fundamento }\end{array}$} & Geografia Humana & Francês & \\
\hline & $\begin{array}{l}\text { Inglês ou Alemão } \\
\text { - facultativamente }\end{array}$ & $\begin{array}{l}\text { Inglês ou Alemão } \\
\text { - facultativamente }\end{array}$ & \\
\hline \multirow{6}{*}{$\begin{array}{l}\text { Cursos de } \\
\text { Integração } \\
\text { Profissional }\end{array}$} & & & Introdução ao Ensino \\
\hline & & & Filosofia da Educação \\
\hline & & & Psicologia do Adolescente \\
\hline & & & $\begin{array}{l}\text { Medidas Educacionais, } \\
\text { Organização e Programas } \\
\text { do Ensino Secundário }\end{array}$ \\
\hline & & & Filosofia das Ciências \\
\hline & & & $\begin{array}{l}\text { Prática de Ensino } \\
\text { (aproximadamente um } \\
\text { total de } 11 \text { horas } \\
\text { semanais) }\end{array}$ \\
\hline
\end{tabular}

Fonte: Instruções no 3 da UDF, de 12 de junho de 1935, e Instruções n 16 , de 25 de junho de 1937. Arquivo do Instituto de Educação. (FERREIRA, 2006, p. 146). 
$\mathrm{Na}$ nova estrutura do curso da UDF há uma valorização das disciplinas de Conteúdo em detrimento das disciplinas de Fundamento, de onde foram suprimidas as disciplinas de Antropologia, Desenho, Biologia Educacional e Sociologia Educacional. Ela observa, ainda, uma predominância, em ambos os currículos, das disciplinas de História Universal, sendo as de História Moderna e História Antiga as mais valorizadas, com uma carga horária de seis e cinco horas semanais, respectivamente, o que ela atribui ao foto de serem as cadeiras dos professores franceses Henri Hauser e Eugene Albertini, que gozavam de maior prestígio naquele período. As disciplinas de formação pedagógica continuavam tendo um peso bastante grande, o que revela que o curso, desde o princípio, foi concebido para formar professores secundários. Nessa nova estrutura, também houve uma valorização das atividades de pesquisa, tendo sido criada uma disciplina específica (Pesquisas Históricas e Bibliografia) no terceiro ano. Um outro aspecto que a autora chama a atenção é o fato de a cadeira de História da Civilização no Brasil ser pouco valorizada nas duas estruturas, sendo reservada a ela uma carga horária semanal de apenas três horas no segundo ano, enquanto as disciplinas de História Universal tinham uma carga horária de 15 horas semanais na primeira estrutura (de 1935) e de 18 horas semanais na nova estrutura (FERREIRA, 2006).

Em 1937, com a instalação do Estado Novo, a UDF, que seguia orientações diversas das do Ministério da Educação, foi fechada, e a maioria dos seus cursos foi integrada à Faculdade Nacional de Filosofia, Ciências e Letras (FNFi) da Universidade do Brasil (UB) em 1939. A nova universidade foi organizada em quatro seções: Filosofia, Ciências, Letras e Pedagogia. $O$ curso de História, que foi estruturado junto com o curso de Geografia, integrava a Seção de Ciências em associação com os cursos de Matemática, Física, Química, História Natural e Ciências Sociais. A partir de então, a estrutura curricular do curso passou a ser a seguinte: 


\begin{tabular}{|c|c|c|c|}
\hline Ano & Primeiro & Segundo & Terceiro \\
\hline \multirow{4}{*}{ Disciplinas } & Geografia Física & Geografia Física & Geografia do Brasil \\
\cline { 2 - 4 } & Geografia Humana & Geografia Humana & História Contemporânea \\
\cline { 2 - 4 } & Antropologia & História Moderna & História do Brasil \\
\cline { 2 - 4 } & $\begin{array}{c}\text { História da Antiguidade } \\
\text { e Idade Média }\end{array}$ & História do Brasil & História da América \\
\cline { 2 - 5 } & & Etnografia & Etnografia do Brasil \\
\hline
\end{tabular}

Fonte: Ata da Faculdade Nacional de Filosofia de 15 de outubro de 1946. Arquivo Gustavo Capanema, CPDOC/FGV, FNFi-CG g 1936.01.18. (FERREIRA, 2006, p. 153).

Grandes modificações foram implementadas no curso de História da nova faculdade, tanto na estrutura organizacional quanto na própria concepção de História. O novo curso, agora de Geografia e História, foi organizado em três anos em 1939, sendo ampliado para quatro anos em 1946. As disciplinas deixaram de ser denominadas História da Civilização no Brasil e História da Civilização na América para serem chamadas de História do Brasil e História da América, fato que revela uma orientação do governo Vargas de valorizar a história política nacional com a exaltação dos grandes personagens da memória nacional, o que contrariava aquela preocupação internacional de não instigar nacionalismos exacerbados. Além disso, o novo curso separava as disciplinas de formação pedagógica (concentradas na Faculdade de Educação), que poderiam ser cursadas após a conclusão das disciplinas específicas, dando aos alunos, assim como na Faculdade de Filosofia, Ciências e Letras da USP, duas opções de formação: o Bacharelado e a Licenciatura.

Além das duas opções de formação, pode-se observar que a nova estrutura curricular do curso também ficou bastante semelhante à estrutura do curso da USP de 1942, talvez pelo fato de o novo curso basear-se, assim como aquele, no Decreto Federal no 1.190, que criava as cadeiras de Geografia Física, Geografia Humana, História da Civilização Antiga e Medieval e História da Civilização Moderna e Contemporânea.

A partir de 1946, o curso de Geografia e História da FNFi foi ampliado de três para quatro anos, passando a ter a seguinte estrutura curricular: 


\begin{tabular}{|c|c|c|c|c|}
\hline Ano & Primeiro & Segundo & Terceiro & Quarto \\
\hline \multirow{4}{*}{ Disciplinas } & Geografia Física & Geografia & Geografia do & História \\
\cline { 2 - 5 } & Geografia & Geografia & História Moderna & História do Brasil \\
\cline { 2 - 5 } & Antropologia & $\begin{array}{c}\text { História da } \\
\text { Idade Média }\end{array}$ & História do Brasil & Eletivas \\
\cline { 2 - 6 } & História Antiga & & História da & \\
\cline { 2 - 6 } & & Etnografia & $\begin{array}{c}\text { Etnografia do } \\
\text { Brasil }\end{array}$ & \\
\hline
\end{tabular}

Fonte: Ata da Faculdade Nacional de Filosofia de 15 de outubro de 1946. Arquivo Gustavo Capanema, CPDOC/FGV, FNFi-CG g 1936.01.18. (FERREIRA, 2006, p. 153).

Essa nova estrutura também mantinha bastante semelhança com a estrutura curricular de 1946 do curso da USP, inclusive com a introdução, no quarto ano, de disciplinas eletivas, que na USP eram chamadas de disciplinas optativas.

Bastante distinto do curso de História da UDF, que era pautado numa concepção histórica voltada para a defesa de uma história social da civilização, o curso de Geografia e História da FNFi (e, pelo que podemos deduzir, também o curso da USP) baseava-se numa concepção de história política voltada para a valorização da identidade nacional, por meio do fortalecimento da unidade nacional e do culto aos grandes heróis nacionais como construtores da nação (FERREIRA, 2006).

Essa concepção de história e esse tipo de organização curricular iriam permanecer por muito tempo ainda no Brasil, principalmente porque esses dois cursos (o da FNFi e o da USP) serviriam de inspiração para vários outros criados no país nesse período e nas décadas posteriores. Vários deles foram criados isoladamente (por estados e municípios) e depois incorporados por universidades federais ou estaduais.

\section{Mapa dos Cursos Superiores de História no Brasil}

Atualmente, existem mais de 600 cursos de História em funcionamento no país, oferecidos por instituições públicas e privadas. No entanto, pouco se sabe a respeito do processo de institucionalização desses cursos. Aliás, poucos têm sido os trabalhos dedicados à institucionalização dos cursos superiores no Brasil, mesmo com relação aos de História, que, 
por sua própria natureza, poderiam instigar esse tipo de estudo. Além dos trabalhos de Roiz (2004) e Ferreira (2006), que tratam da criação dos cursos da USP e da UDF, respectivamente, foram levantados os estudos de Rodrigues (2002) e Borges (2006) sobre os cursos da Universidade Federal de Goiás (UFG) e da Universidade Federal do Rio Grande do Sul (UFRGS), respectivamente. Assim, restringimo-nos aqui a apresentar os anos e os locais de institucionalização dos cursos presenciais mantidos por instituições públicas (municipais, estaduais ou federais) e o grau de formação possibilitado por eles.

São 286 cursos registrados no banco de dados do INEP. Bacharelados e licenciaturas são registrados separadamente, mesmo quando oferecidos pela mesma instituição. Supõe-se que isso se deva à adequação dos cursos feita após as determinações das Diretrizes Curriculares Nacionais para a Formação de Professores da Educação Básica, regulamentadas pelo Parecer CNE/CP 009/2001 ${ }^{14}$. Até 2001, bacharelado e licenciatura eram oferecidos em um mesmo curso, com a possibilidade de obtenção dos dois graus. Normalmente, concluía-se o primeiro e, depois de cursadas as disciplinas de caráter pedagógico, obtinha-se, também, o grau de Licenciado. A partir da nova regulamentação, os cursos de licenciatura, não só de História, mas de todas as outras áreas do conhecimento, deveriam ser oferecidos independentemente dos cursos de bacharelado. A justificativa era que se fazia necessário criar uma identidade própria para os cursos de formação de professores, fugindo-se do modelo tradicional, no qual se privilegiava a formação do bacharel em detrimento da formação do professor, tratando a formação pedagógica como mero apêndice da formação específica. De lá para cá, a maioria das instituições readequou seus Projetos Pedagógicos de Curso (PPC) para atender as novas regulamentações. Embora o debate sobre essas questões possa ser profícuo, não se pretende aqui discutir as implicações desse novo modelo para a formação do profissional da História (Licenciado ou Bacharel): objetiva-se apenas apresentar as primeiras

14 O Parecer CNE/CP 009/2001, aprovado em 08/05/2001 pelo Conselho Nacional de Educação, define as "Diretrizes Curriculares Nacionais para a Formação de Professores da Educação Básica, em nível superior, curso de licenciatura, de graduação plena". 
informações levantadas sobre esses $\operatorname{cursos}^{15}$.

Não obstante muitos cursos de bacharelado e licenciatura terem sido criados como curso único, para a elaboração dos gráficos, eles foram considerados separadamente, pois os registros do INEP os tratam como cursos independentes. Além disso, por conta da nova legislação, bacharelados e licenciaturas têm cargas horárias ${ }^{16}$ diferentes e, muitas vezes, são oferecidos em turnos alternados.

Do surgimento dos primeiros cursos, na década de 30, até o final da década de 70, foram criados 88 cursos por instituições públicas em todo 0 país. Na década de 80 , esse número praticamente duplicou, pois foram instituídos mais 54 cursos. No entanto, o grande "boom" ocorreu nos anos 2000, quando entraram em funcionamento mais 111 cursos. O gráfico 1 mostra a quantidade de cursos de História criados no país da década de 1930 à de 2000 .

Gráfico 1: Quantidade total de cursos criados por década no país.

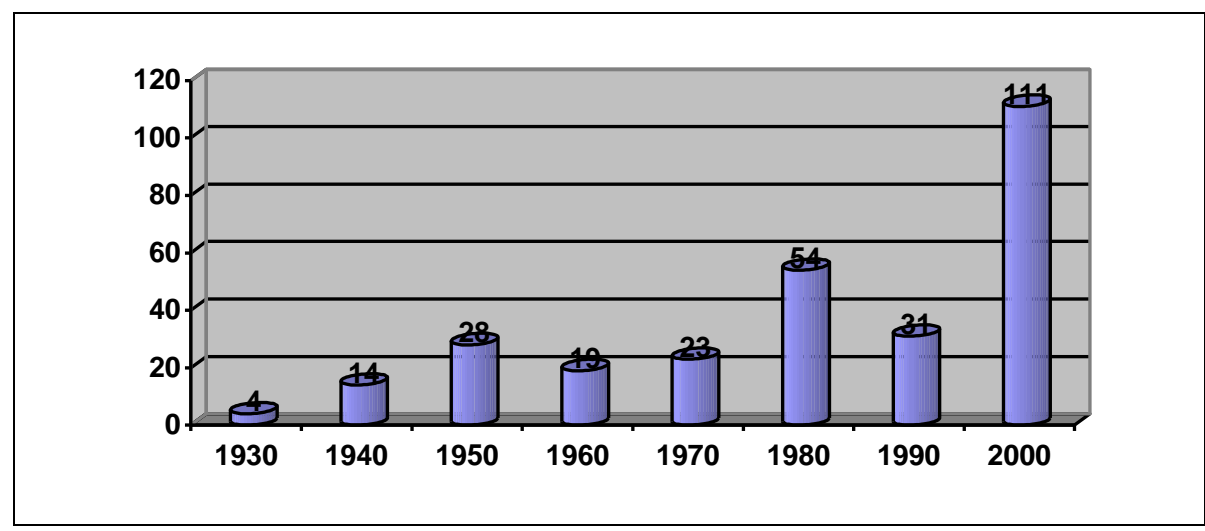

Como se pode observar nos gráficos 3 a 7, a grande quantidade de cursos na década de 80 se deve, sobretudo, aos cursos criados nas regiões Norte (14), Nordeste (13) e Centro-Oeste (13), o que pode ser explicado,

15 Essas informações foram levantadas dentro do projeto de pesquisa "Caminhos da institucionalização do ensino superior de história no Brasil", desenvolvido no Núcleo de Estudos e Pesquisas em Ensino e Formação de Professores (NUFOR) da Universidade Federal do Tocantins, Campus de Araguaína.

16 As resoluções no 2, de 19/02/2002, e no 2, de 18/06/2007, do Conselho Nacional de Educação, estipulam as cargas horárias mínimas dos cursos de licenciatura e bacharelado em 2.800 e 2.400 horas, respectivamente. 
em primeiro lugar, pelo déficit de cursos dessas regiões, que só instituíram seus primeiros cursos a partir das décadas de 70 e 80; em segundo lugar, pela abertura política do país, que permitiu a autorização de funcionamento de um maior número de cursos, sobretudo pelos governos estaduais. Além disso, esse período também é marcado por uma maior organização de sindicatos e associações de classe, levando os trabalhadores da educação a se organizarem e a promoverem movimentos em favor da profissionalização docente. Já a explosão de cursos nos anos 2000 pode ser explicada principalmente pela exigência da nova legislação. É importante lembrar que a nova Lei de Diretrizes e Bases da Educação (LDB), aprovada em 1996, determinava a formação em nível superior para todos os professores da educação básica ${ }^{17}$. Assim, especialmente os estados que tinham um déficit maior de professores com formação superior tiveram que criar cursos, com o objetivo de acelerar o processo de formação docente.

As tabelas de 3 a 7 apresentam o crescimento do número de cursos de História por década em cada região.

Tabela 1: Cursos criados em instituições públicas por estado da região Norte.

\begin{tabular}{|l|c|c|c|c|c|c|}
\hline & $\mathbf{1 9 5 0}$ & $\mathbf{1 9 6 0}$ & $\mathbf{1 9 7 0}$ & $\mathbf{1 9 8 0}$ & $\mathbf{1 9 9 0}$ & $\mathbf{2 0 0 0}$ \\
\hline AC & 0 & 0 & 2 & 0 & 0 & 4 \\
\hline AM & 0 & 0 & 0 & 1 & 0 & 3 \\
\hline AP & 0 & 0 & 0 & 3 & 0 & 0 \\
\hline PA & 2 & 0 & 0 & 9 & 4 & 3 \\
\hline
\end{tabular}

Observa-se que na região Norte, até o final da década de 70, havia apenas dois cursos de história funcionando em instituições públicas: um no Pará, criado em 1954, e um no Acre, em funcionamento a partir de 1976. Somente na década de 80 foram criados os primeiros cursos de História nas universidades dos estados do Amazonas (1981), de Rondônia (1983) e do Tocantins (1985), que na época ainda fazia parte do estado de Goiás. Os estados de Roraima e Amapá - territórios nacionais até 1988 - criaram seus primeiros cursos apenas em 1990. A partir da década de 80 , houve um

17 O artigo 62 da LDB/1996 define que "A formação de docentes para atuar na educação básica far-se-á em nível superior, em curso de licenciatura, de graduação plena, em universidades e institutos superiores de educação [...]". 
crescimento significativo no número de cursos nessa região, sobretudo no estado do Pará, que só naquela década registrou a criação de nove cursos.

Nos estados do Nordeste, os primeiros cursos foram criados na Bahia (1941), no Ceará (1947) e em Pernambuco (1950), seguidos das demais capitais: Aracaju/SE (1951), Maceió/AL e João Pessoa/PB (1952), São Luís/MA (1953), Natal/RN (1957) e Teresina/PI (1958). Se comparado às demais regiões do país, o Nordeste registrou um número bastante reduzido de aberturas de cursos nas décadas de 80 e 90, quando foram criados, respectivamente, 12 e 17 cursos nos nove estados da região. No entanto, nos anos 2000, a região registrou um crescimento de mais de $90 \%$, saltando de 63 cursos até o final de 1990 para 121 em 2010. O estado que mais contribuiu para esse aumento foi o Maranhão, que só nos anos 2000 criou 41 novos cursos.

Tabela 2: Cursos criados em instituições públicas por estado da região Centro-Oeste.

\begin{tabular}{|l|c|c|c|c|c|}
\hline & $\mathbf{1 9 6 0}$ & $\mathbf{1 9 7 0}$ & $\mathbf{1 9 8 0}$ & $\mathbf{1 9 9 0}$ & $\mathbf{2 0 0 0}$ \\
\hline DF & 2 & 0 & 0 & 0 & 0 \\
\hline GO & 2 & 0 & 9 & 5 & 10 \\
\hline MS & 0 & 3 & 1 & 0 & 4 \\
\hline MT & 0 & 0 & 2 & 2 & 0 \\
\hline
\end{tabular}

Na região Centro-Oeste, os primeiros cursos foram criados no final dos anos 60, em Brasília/DF (1967) e Goiânia/GO (1968). No estado de Goiás, após a criação do primeiro curso em Goiânia, em 1968, só foram criados novos cursos a partir de meados da década de 80 , quando houve a abertura de vários deles em cidades do interior do estado pela Universidade Estadual de Goiás, totalizando nove cursos.

Tabela 3: Cursos criados em instituições públicas por estado da região Sul.

\begin{tabular}{|l|c|c|c|c|c|c|c|c|}
\hline & $\mathbf{1 9 3 0}$ & $\mathbf{1 9 4 0}$ & $\mathbf{1 9 5 0}$ & $\mathbf{1 9 6 0}$ & $\mathbf{1 9 7 0}$ & $\mathbf{1 9 8 0}$ & $\mathbf{1 9 9 0}$ & $\mathbf{2 0 0 0}$ \\
\hline RS & 0 & 2 & 0 & 2 & 2 & 1 & 0 & 3 \\
\hline SC & 0 & 0 & 2 & 0 & 0 & 5 & 1 & 5 \\
\hline PR & 2 & 2 & 5 & 3 & 2 & 0 & 2 & 2 \\
\hline
\end{tabular}

Os primeiros cursos de História criados na região Sul foram os do 
Paraná (1938) e do Rio Grande do Sul (1943). O estado de Santa Catarina só instituiu seu primeiro curso em 1959. O Paraná foi o estado que criou o maior número de cursos na região, possuindo nove cursos já na década de 50. No mesmo período, Santa Catarina e Rio Grande Sul possuíam apenas dois cursos cada. Aliás, esses dois últimos estados só vieram a criar um segundo curso em 1965 (RS) e 1987 (SC). Atualmente, funcionam na região 41 cursos (14, 3\% do total de cursos do país), sendo 18 no Paraná, 13 em Santa Catarina e 10 no Rio Grande do Sul.

Tabela 4: Cursos criados em instituições públicas até 2003 por estado da região Sudeste.

\begin{tabular}{|l|c|c|c|c|c|c|c|c|}
\hline & $\mathbf{1 9 3 0}$ & $\mathbf{1 9 4 0}$ & $\mathbf{1 9 5 0}$ & $\mathbf{1 9 6 0}$ & $\mathbf{1 9 7 0}$ & $\mathbf{1 9 8 0}$ & $\mathbf{1 9 9 0}$ & $\mathbf{2 0 0 0}$ \\
\hline SP & 1 & 0 & 1 & 2 & 2 & 0 & 0 & 1 \\
\hline RJ & 1 & 3 & 0 & 0 & 0 & 1 & 1 & 4 \\
\hline MG & 0 & 2 & 2 & 3 & 0 & 2 & 1 & 9 \\
\hline ES & 0 & 0 & 2 & 0 & 0 & 0 & 1 & 0 \\
\hline
\end{tabular}

$\mathrm{Na}$ região Sudeste, os primeiros cursos de História foram criados na década de 1930 (USP, 1934; UDF, 1935). O Espírito Santo foi o último estado dessa região a criar um curso de História em instituição pública, em 1953, e manteve-se com apenas um curso até 2003, quando outro foi instituído pela Faculdade de Filosofia, Ciência e Letras de Alegre, instituição municipal. O estado de São Paulo é o que registra o menor número de cursos na região, com apenas sete, e o estado de Minas Gerais é o que tem o maior número de cursos, com 19. Nos registros sobre o Rio de Janeiro, foram encontrados 12 cursos; no entanto, foram apresentados no gráfico apenas 10, pois os cursos de licenciatura e bacharelado de Campos dos Goytacazes, mantidos pela UFF, não possuíam nenhum registro sobre início de funcionamento ou atos regulatórios.

Os gráficos 2 e 3 mostram a distribuição dos cursos por unidade da federação e o número de bacharelados e licenciaturas por regiões. 
Gráfico 2: Distribuição dos cursos pelas unidades da federação.

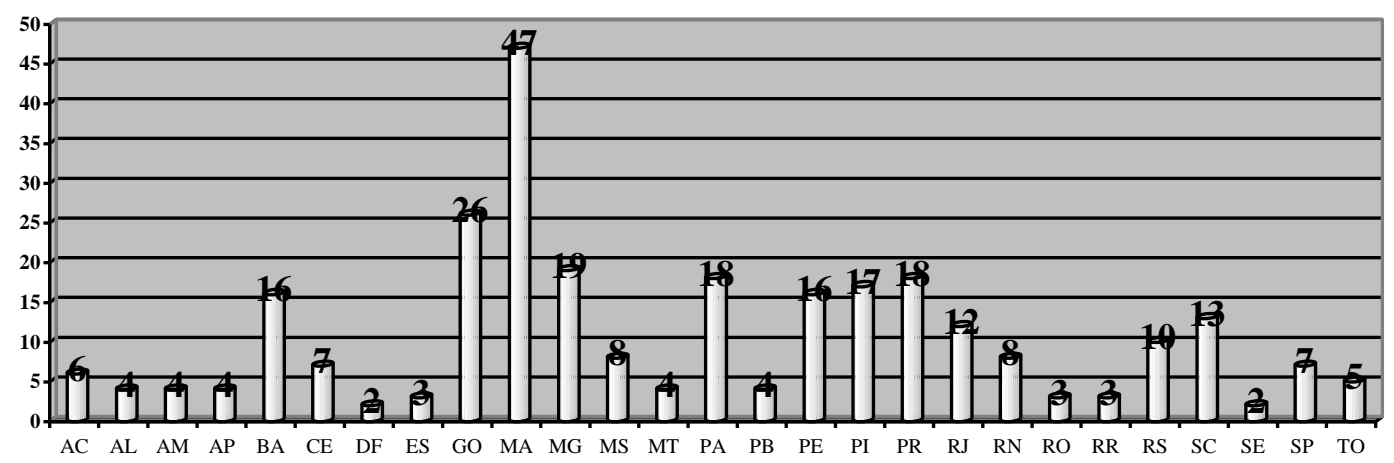

Gráfico 3: Divisão dos cursos por grau de formação por regiões em 2010.

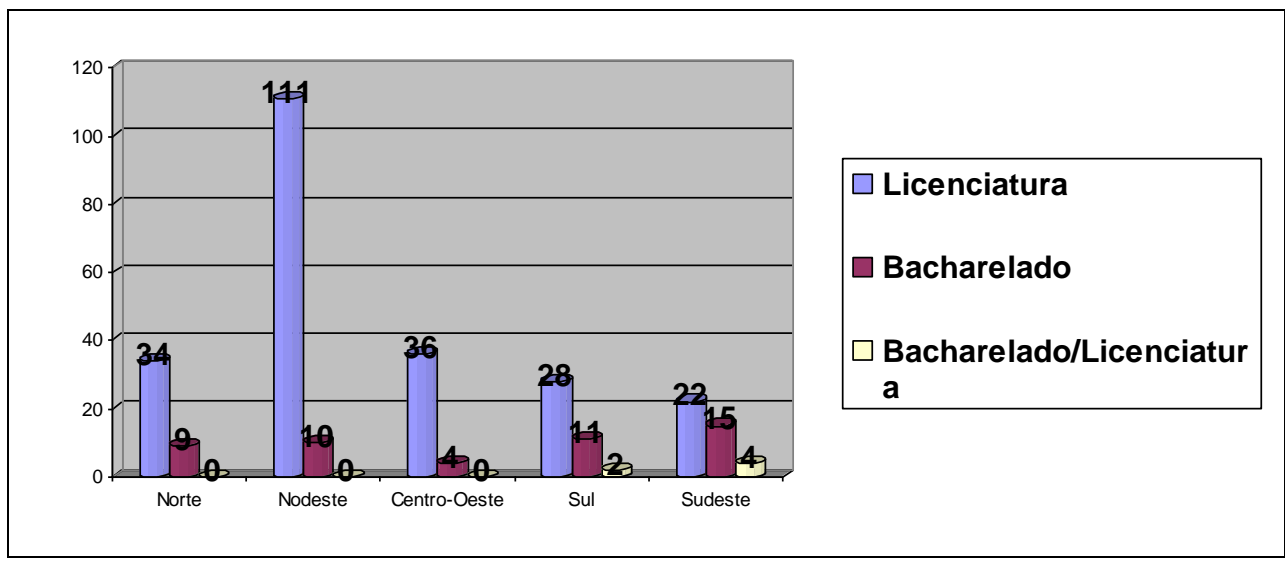

Observa-se que o maior número de cursos está concentrado na região Nordeste, com 121 cursos (42,3\%), sendo mais de $90 \%$ deles de licenciatura, seguida da região Norte, com 43 cursos (15\%), e das regiões Centro-Oeste, Sul e Sudeste, com pouco mais de $14 \%$ cada. Pode parecer estranho que as regiões mais desenvolvidas economicamente tenham um número menor de cursos superiores de História oferecidos por instituições públicas; no entanto, isso pode ser explicado pelo grande número de cursos oferecidos nessas regiões por instituições privadas ${ }^{18}$. Já nas regiões que apresentam um menor desenvolvimento econômico, o número de cursos em instituições públicas supera o número de cursos em instituições

18 As análises preliminares sobre os cursos mantidos por instituições privadas revelam que a maioria deles se concentra nas regiões Sul e Sudeste do país. 
privadas, especialmente em estados como Pará, Piauí e Goiás, cujo processo de criação dos cursos ocorreu tardiamente, apenas a partir da segunda metade da década de 1980.

Nosso objetivo, como já foi dito, é apenas apresentar um retrato dos cursos de História no Brasil. Ressaltamos, no entanto, que as informações disponíveis nos bancos de dados do Instituto Nacional de Pesquisas Educacionais Anísio Teixeira (INEP), do Ministério da Educação (MEC), permitem uma série de análises que podem ser bastante úteis para os profissionais da História e da Educação. Além dos dados apresentados, há outros sobre carga horária, turno de funcionamento, quantidade de vagas oferecidas, regime de funcionamento e prazo de integralização dos cursos. Esses dados podem elucidar o perfil dos cursos e, se cruzados, por exemplo, com os dados do ENADE ${ }^{19}$, podem revelar o perfil dos estudantes e a quantidade de profissionais formados anualmente no país. Além disso, há a possibilidade de cruzamento com dados sobre governos, políticas e reformas educacionais, avaliações da educação básica, censos educacionais, entre outros, o que possibilitaria uma melhor compreensão do papel que tem ocupado o ensino superior no país, em especial no que concerne à formação de professores. São possibilidades diversas que cabem a nós, profissionais da História, explorar. Possivelmente, muitos estudos dessa natureza já devem estar sendo realizados, mas nunca é demasiado lembrar que trabalhos desse tipo são sempre bem-vindos em um país cuja qualidade da educação tem sido posta em xeque todos os anos, como revelam os resultados dos exames aplicados em todos os níveis de ensino.

\section{Referências}

BORGES, S. A. Os cursos de história da Universidade Católica de Goiás e da Universidade Federal de Goiás: um olhar histórico. 2006. Dissertação (Mestrado em Educação) - Universidade Federal de Goiás, Goiânia, 2006.

19 O Exame Nacional de Desempenho dos Estudantes (ENADE) foi implantado em 2004 pelo Ministério da Educação e faz parte do Sistema Nacional de Avaliação da Educação Superior (SINAES), cujo objetivo é aferir o desempenho dos estudantes dos cursos de graduação. 
CUNHA, L. A. A universidade temporã: o ensino superior, da Colônia à Era Vargas. São Paulo: Ed. Unesp, 2007.

FERREIRA, M. M. Notas sobre a institucionalização dos cursos universitários de História no Rio de janeiro. In GUIMARÃES, M. L. S. (Org). Estudos sobre a escrita da história. Rio de Janeiro: 7 Letras, 2006.

GHIRALDELLI JR. P. História da educação brasileira. 3 ed. São Paulo: Cortez, 2008.

NOIRIEL, Gérard. Naissance du métier d'historien. Genèses, n.1, sept. 1990.

RODRIGUES, M. C. de M. A institucionalização da formação superior em história: o curso de geografia e história da UPA/URGS - 1943-1950. 2002 Dissertação (Mestrado em História) - Universidade Federal do Rio Grande do Sul, Porto Alegre, 2002.

ROIZ, D. S. A institucionalização do ensino universitário de História na Faculdade de Filosofia, Ciências e Letras da Universidade de São Paulo entre 1934 e 1956. 2004. Dissertação (Mestrado em História) - Universidade Estadual Paulista Júlio de Mesquita Filho, Unesp, Franca, 2004.

ROMANELLI, O. O. História da educação no Brasil: (1930-1973). 34 ed. Petrópolis, RJ: Vozes, 2009.

SCHWARTZMAN, S.; BOMENY, H. M. B.; COSTA, V. M. R. Tempos de Capanema. 2 ed. São Paulo: Paz e Terra: Editora FGV, 2000. 